\title{
Direito Internacional Privado e Cultura Pós-Moderna
}

\section{Prof. Dr. Dr. h.c. mult. Erik Jayme}

Excelentíssimo Senhor Diretor da Faculdade de Direito da UFRGS, Excelentíssimo Coordenador do Mestrado em Direito/UFRGS e Excelentíssimo Senhor Juiz de Direito Diretor da Escola Superior da Magistratura do RS, caros colegas, senhoras e senhores:

Anres de falar do tema Direito Internacional Privado e Cultura Pós-Moderna desejo agradecer profundamente esse convite da Faculdade de Direito da UFRGS, falando também em nome de meu assistente Alexander Geckler. Nossas Universidades têm estreitas relações de colaboração e estamos aqui para discutir problemas os mais recentes de direito, os quais se apresentam muitas vezes como semelhantes em nossos países.

Pesscalmente, seja-me permitido mencionat que é a primeira vez que venho ao Brasil e há muito tempo desejava vir. O Brasil é o país dos meus sonhos, país que eu conheci na literatura, nos filmes e, naturaimente, do direito civil e direito internacional privado. Agradeço particularmente à Professora Cláudia Lima Marques, que esteve em Heidelberg para o seu dourorado e que preparou minha primeira estada brasileira.

Durante esta semana teremos várias lições sobre o direiro de familia alemão atual no âmbito da pós-modemidade e espero muitas discussões sobre as questões suscitadas nestas lições.

Senhoras e senhores, passo à conferência:

O objeto - um pouco temerário - dessa conferência é o seguinte: direito internacional privado e cultura pós-moderna. ${ }^{2}$ Durante este curso na UFRGS, serão abordados o direito

1 Versão da aula apresentada na Faculdade de Direito da Universidade Federal do rio Grande do Sul, em 2 de setembro de 1996, como abertura do Curso "Direito Patrimonial de Famélia na Pós-Modernidade". Tradução livre, autorizada e não revista pelo autor, de Lisiane Feiten Wingert (Bacharel em Direito pela UFRGS, Mestranda/UFRGS, Bolsita da CAPES), revisão e notas da Profa. Dra. Claudia Lima Marques, Professora Titular de Direito (UFRGS). A forma oral foi preservada e acrescentadas notas, com base no texto publicado no ano seguinte por Erik Jayme, "Internationales Privatrecht und postmoderne Kultur, in ZFVR-Zeitschrift für die Rechtsvergleichung (Viena) 1997, p. 230-236.

2 Veja Erik Jayme, Idencité culturelle et intégtation: le droit international privé postmoderne, Recheil des Cours 251(1995), 9 ss. 
de familia e também de contratos, em torno da questão geral do direito internacional privado e da cultura pós-moderna.

De início, algumas considerações preliminares: o direito faz parte da cultura geral. Tem raízes profundas na tradição, mas também sofre influências pelo desenvolvimento de nossa sociedade e da comunidade internacional. Dessa maneira, nosso direito atual é, em certa medida, uma reprodução de nossa cultura contemporânea, quer dizer, da cultura pós-moderna. ${ }^{3}$

Se nós falamos do pós-modemismo ou da condição pós-moderna-como chama o autor francês Lyotard $\mathrm{d}^{4}$ nós pensamos inicialmente na arquitetura de nossos dias e em nossa arte. ${ }^{5}$

A arte abstrata da arquitetura do cubismo, concebida ao conhecimento da arte figurativa. ${ }^{6}$ No que concerne à arquitetura de prédios, descreve sua função pelos seus elementos clássicos, bem como pela fachada. De outra parte, podemos notar um pluralismo de estilos, que podemos chamar mesmo de ecletismo, isto é, os artisras escolhem os elementos clássicos, que então são misrurados ou combinados com outros elementos modernos. ${ }^{7}$ Encontramos também movimentos similares na lireratura e na filosofia.

O ponto de encontro entre a cultura pós-moderna e o direito são os valores que têm em comum. ${ }^{8}$ Para essa conferência, permiro-me escolher quatro valores ou elementos demonstrados na cultura pós-moderna.

O primeiro deles, já mencionado, é o pluralismo (Pluralismus). Não apenas o pluralismo de formas, mas também de estilos. E também de estilos de vida, é a idéia de autonomia em escolher seu próprio modo de vida. O mundo pós-moderno é caracrerizado por um "direito à diferença" (droit à la difference), para citar a expressão do senhor professor R.-J. Dupuy, do colégio de França, atualmente presidente do Instituto de Direito Inrernacional."

O segundo valor: o mundo pós-moderno é caracterizado pela comunicação (Kommunikation) e por não ter mais fronteiras. De outra parte, não são apenas os meios tecnológicos que permitem a rroca rápida de informação e imagens, mas também a vontade (Wille) e o desejo (Wunsch) de se comunicar dessas pessoas. Esse desejo emerge como valor comum. ${ }^{10}$

A terceira característica é a "narração" (Narration)"1" comunicar é também descrever, contar, narrar, observe-se o já alto nível da arte figurativa.

3 Veja Remo Ceserani, Raccontare il postmoderno (Torino, 1997), p. 127.

* Veja Jean-François Lyotard, La condition postmoderne (Paris 1979), p. 8 ss.

5 Sobre a volta de elementos clássicos na arquitetura de Berlim, veja reportagem "Hauptstadt Renaissance: Aldo Rossis Berlin", in Frankfurter Allgemeine Zeitung 9.9.1997, p. 42.

"Sobre arte figurativa e as recordações, Jayme, ZfRV 1997, p. 232.

- Veja sobre o elemento central da arquitetura pós-modetna, o 'double coding', Charles Jencks, What is Postmodemism? (3.Ed., Londres/New york 1989), p. 14.

8 Lyotard, nota 88: "La science postmoderne comme techerche des instabilités."

" Expressão de René-Jean Dupuy, La clôture du système international. La cité terrestre (Paris 1988), p. 115.

10 Veja detalhes in Erik Jayme, e "Internationales Privatrecht und postmoderne Kultur, in ZfVR. Zeitschrift für die Rechtsvergleichung (Viena) 1997, p. 231.

1t A narração legitima também a ciência, veja discussóes de Lyotard e Steven Connox, in Postmodernist Culture (Oxford 1989), p. 2 e seg. 
O quarto valor é o retomo dos sentimentos (le retour des sentiments, Rückkebrder Gefüble), ${ }^{12}$ algumas vezes descrito em um sentido pejorativo, como emergência de um novo irracionalismo. Podemos, porém, constatá-lo em relação à identidade cultural, que pode conduzir a conflitos culturais, baseados em um sentimento forte de defesa de sua própria identidade cultural, de sua religião e de todas as outras expressões do individualismo.

A escolha desses quatro valores da cultura pós-moderna - plutalismo, comunicação, natração e retorno dos sentimentos - pode parecer arbirrária, mas essa escoll a permite pôr em evidência a ligação entre o direito e a cultura pós-moderna. ${ }^{13}$

Entre as matérias de direito, ${ }^{14}$ escolho o direito internacional privado - o direito do conflito das leis - que compreende hoje em dia também o conflito de jurisdição, as questões de processo em matétia de competência e execução de julgamentos estrangeiros. ${ }^{15}$

O Direito Internacional Privado clássico tem como finalidade principal a garantia da harmonia na comunidade jurídica internacional e na execução de decisões estrangeiras. É um ideal formal e objetivo, devido à autoridade de grandes autores do século XIX como, por exemplo, Savigny. A justiça conflitual baseia-se na idéia de conexão (Anknüpfung), no caso concreto, com um país, que justifique a aplicação do direito desse país, qualquer que seja o resultado concreto da aplicação dessa norma. ${ }^{16}$

Crítica a essa idéia desenvolveu-se na doutrina moderna, sobretudo com os autores americanos, que favoreceram com uma certa materialização (Materialisierung des Kollisionsrechts) do direito internacional privado, no sentido de que a melhor lei (em inglès, better law) ${ }^{17}$ - a lei mais favorável ao sujeito mais vulnerável - deve ser a aplicada. Por exemplo, a lei que melhor protege a vítima de um acidente. Aqui, a finalidade material da norma (Sachnormen und ibre Zwecke) tem precedência e leva à flexibilização dos métodos do direiro internacional privado. ${ }^{18}$

Passamos agora ao tema objetivamente proposto para esse trabalho.

As coisas mudaram: existem fenômenos novos na visão pós-moderna do direito internacional privado e que refletem os quatro valores expostos no início dessa apresentação.

12 Veja Jayme, Recueil des Cours, p. 36 e 261 ss. E veja também Arthur Kaufmann, Rechstpbilosopbie in der Nach-Neuzeit (Fleidelberg 1990), p. 6.

13 Veja defesa desta decisão in Jayme, Recueil des Cours, p. 36ss.

:4 Veja por exemplo Ladeur, Post-modern Constitutional Theory: A propect for the self-organising sociery, The Modern Law Review 60 (1997), p. 617.

!5 Veja detalhes in Jayme, ZRRV 1997, p. 232.

${ }^{16}$ Jayme, ZRRV 1997, p. 232.

"Veja Erik Jayme, Diritto cparato e teoria del progresso, Rivista del Diritto Commerciale e del Diritto Generale delle Obligazione, nr. 1-2/3-4 (gennaiomaprile) 1995,p. 45ss.

${ }^{18}$ Assim Jayme, ZfRV 1997, p. 232: "Das Internatonale Privatrecht hatte nach der klassischen eine modeme Phase. Diese bestand in einer gewissen Materialisierung des Kolisionsrechts. Waren in der klassischen Zeit die Kollisionsnormen Instrumente eines autonomen Verweisungsrechts, so traten in der moderne die Sachnormen und ihre Zwecke in den Vordergrund. Es kam zu einer Vermischung der Kategorien. Die Suche nach der Gerechtigkeit des Einzelfalles verdrängte übergeordnete Ziele, wie die Rechtssicherheit und die Vorhersehbarkeit. Ergebnisbestimmte, flexible Kollisionsnormen waren die Folge." 
Para ilustrar esse fenômeno, permito-me mencionar dois casos da Corte Federal alcmã (BGH): um caso alemão-brasileiro e uma decisão inglesa.

O primeiro caso, datado de 28 de fevereiro de 1996, da Corte Federal alema , $^{19}$ concerne ao seguinte: um alemão demanda o pagamento de uma soma $\mathrm{cm}$ dinheiro e a restituição de alguns bens, entre os quais um automóvel, ern razão de ruptura de noivado. A demandada, urna brasileira, doniciliada na Espanha.

A pretensão se baseava em vários dispositivos, como entiquecimento sem causa, responsabilidade por delito e revogação de doação.

As partes viveram juntas por um periodo e por duas vezes fixaram a data para a realização da cerimônia de casamento. A parte demandada, a brasileira, não apenas renunciou ao casamento no último momento, como também teve um filho no Brasil - cujo pai não era o noivo, mas outro homem.

A primeira questão importanre é saber se os tribunais alemães eram competentes para apreciar esse caso, uma vez que há limites quanto à competência internacional dos tribunais alemães em questão de eventual responsabilidade delitual da parte ré - apesar de que os outros fundamentos, sobretudo a demanda baseada no enriquecimento sem causa, não se inclúam na competência dos tribunais alemães.

A Corte motivou sua decisão da seguinte maneira: primeiro, explicou que a Convenção de Bruxelas sobre jurisdição e execução de julgamentos não é aplicável a esse caso, uma vez que as causas que derivam de rupturas da noivados estão excluídas do campo da aplicação dessa convenção; em segundo lugar, porque, ao momento da demanda, a Convenção de Bruxelas não estava em vigor entre a Espanha e a República Federal da Alemanha.A Corte, então, aplicou a lei nacional, quer dizer, o Código de Processo Civil alemão. De outra parte - e nós nos aproximamos agora do pós-modernismo - a Corte aplicou normas da Convenção por analogia. ${ }^{20}$

A Convenção de Bruxelas não favorece o demandante. Existem algumas exceções como, por exemplo, formas contratuais, lugar de execução das obrigações etc. Mas essas exceções são interpretadas pela Corte de Justiça da Comunidade Européia de maneira restritiva: A Corte justificou a aplicação desse princípio da Convenção de Bruxelas pelo interesse da comunidade dos estados europeus em alcançar princípios comuns e uniformes nos procedimentos civis. ${ }^{21}$

${ }^{19}$ BGH 28.2.1996, NJW 1996,p. 1411, também in IPRAX 1997, p. 187; veja Peter Mankowski, Verlöbrisbruch, konkuriende Deliktsansprüche und Rückfordetung von Geschenken im Internationalen Privat- und Zivilprozessrecht, IPRAX 1997, p. 174.

${ }^{20}$ O texto da decisão, no original reproduzido in ZFRV 1997, p. 233 é: "Das gebietet das Interesse des internationalen Rechtsanwendungseinklang und der Einheitlichkeit der. Auslegung von Staatsvertägen (...). Es wäre nicht vesrtändlich, eine intemationale Zuständigkeit kraft Sachzusammenhangs in Fällen, die der: Geltung des EuGVÜ unterliegen, auszuschliessen, sie dagegen in F̈̈̈llen ausserhalb seines Geltungsbereichs allgemeinen zuzulassen, obwohl das Interesse der Europäischen Staatengemeinschaft gerade darauf abzielt, in Fällen mit auslandsbezug zu möglichst einheitlichen Verfalırensgrundsätzen zu gelangen."

${ }^{21}$ Veja também Erik Jayme, Staatsverträge als ratio scripta im Internationalen Privatrecht, in: Collisio Legum, Fs Broggini (Mailand 1997), p. 211. 
Senhoras e senhores: à primeira vista, a aplicação de uma convenção internacional que nâo está em vigor pode parecer um absurdo. Por outro lado, esse método (normas narrativas) ${ }^{22}$ faz parte do direito internacional privado pós-moderno.

As regras de um tratado internacional assumem duas funções: a primeira função, no que concerne às questões da própria convenção, onde tem força obrigatória; a segunda função, narrativa. Isto quer dizer, os princípios enunciados pela Convenção podem ser tomados em consideração, para decidir questões que a Convenção reserva ao direito nacional.

Afirmei que esse fenômeno é narrativo - e não é o único caso. Existem outros casos com o mesmo método, inclusive o que um caso recente da Corte Suprema Austriaca, em que foi aplicada a Convenção de Lugano, a qual não estava em vigor ao momento da decisão. ${ }^{23}$

É chegado o momento de efetuar algumas observações no que tange à teoria: o sisrema jurídico pressupõe uma certa coerência - o direiro deve evitar contradição. O juiz, na presença de duas fontes - uma européia transnacional e outra nacional - com valores contrastantes, deve buscar coordenar as fontes, num diálogo das fontes (Dialog der Quellen). ${ }^{24}$

O direito europeu agora favorece o réu, conforme o princípio geral da Convenção de Bruxelas, que indica o domicílio do réu; enquanto o direito alemão nacional favorece - um pouco, mas favorece claramente - a parte demandante.

Há um conflito de valores e a Corte Federal resolveu esse conflito de valores da seguinte maneira: preferiu o direito europeu, a fim de buscar uma uniformidade de soluções no sistema europeu. ${ }^{25}$

Existem nesse julgado outras questões interessantes: mencionei o problema de ruptura do noivado, onde se trata também de determinar a lei aplicável a essa ruptura. A Lei de Introdução ao Código Civi Alemão (EGBGB) não prevê regra escrita sobre a lei aplicável a noivados. De outro lado, a Corte Federal favoreceu o princípio da nacionalidade, quer dizer, aplicada a lei da nacionalidade da demandada, brasileira.

É muito interessante observar a Corte alemã aplicando a lei brasileira, justamente porque a demandada com domicilio na Espanha tem nacionalidade brasileira. Vê-se que no mundo do direito internacional privado há um conflito eterno entre o princípio da nacionalidade (do direito alemão) e o princípio do domićlio (do direito braisleiro).

Em tempos pós-modernos, para proteger a identidade cultural (kulturelle Identität), ${ }^{26}$

22 Veja a criação desta expressão, in Erik Jayme, Narrative Normen im Internationalen Privat. und Verfahrensrecht (Tübingen 1993). E tambétn Rouhette, Le style de la loi: normes narratives et normes contraignantes, in Académie Internationale de Droit Comparé, Rapports généraux XIVe Congrès Internationale Athènes 1994 (Athen/Den Haag 1996), p. 37.

${ }^{23}$ Veja casos anteriores in Erik Jayme e Alexander Geckler, österreich und das Europäische Kollisionsrecht: Die Parallelität als Rechtsfrage, IPRAX 1993, p. 131 e seg.

${ }^{24}$ Jayme, ZfRV 1997, p. 235.

25 Jayme, Statsverträge als ratio scripta im Internationalen Privatrecht, in: Collisio Legum, Fs Broggini (Malland 1997), p. 211.

26 Jayme, ZRRV 1997, p. 234. 
preferimos novamente o princípio da nacionalidade - que está sendo renovado e renascendo - tal como vemos nessa decisão da Corte Federal Alemã que indicou aplicável a lei brasileira ao caso de ruptura de noivado, em virtude da nacionalidade da demandada.

Retornando ao valor "narração", gostaria de mencionar também um caso inglês, recente e muito interessante, no qual encontramos a mesma técnica de normas narrativas. ${ }^{27}$ Trata-se de um conflito de competência inter-local, uma vez que o Reino Unido tem diferentes unidades territoriais com leis próprias - a Inglaterra e a Escócia, nesse caso.

Em um tribunal inglês, um banco inglês foi demandado para restituição de uma soma paga por uma autoridade escocesa, com base num contrato, que era nulo. A questão era saber se um juiz inglês é competente para o julgamento de um caso como esse. O Reino Unido, em lei especial, prevê a aplicação de regras da Convenção de Bruxelas também para a resolução de conflitos inter-locais.

A parte ré, domiciliada na Escócia, tem uma única possibilidade de encontrar uma base para competência judicial de juízes ingleses, que é o artigo 5 , número $1^{28}$ da Convenção de Bruxelas, que prevê para as obrigações contratuais, a competência no lugar de execução de contratos.

O ponto em questão é determinar se essa disposição deve ser considerada, ainda que nulo o contrato, no sentido do que prescreve o art. $5^{\circ}, 1$ da Convenção de Bruxelas incorporada no Reino Unido. Ou seja, uma obrigação constante de um contrato nulo é uma obrigação contratual, ou não?

A Corte decidiu que juizes ingleses eram competentes, tomando em consideração a Convenção de Roma sobre as Leis Aplicadas às Obrigações Contraruais, assumindo as consequiências da nulidade do contrato quanto à lei aplicável ao contrato.

Dessa maneira, a Corte resolveu a questão da competência judicial nesse caso inglês-escocês, em relação a duas convenções européias - a de Bruxelas e de Roma. O direito convencional assumiu, assim, um papel de argumentação, figurando essa disposição como norma narrativa. ${ }^{29}$

Vemos essa tendência de tomar em consideração as convenções nos casos nacionais - aos quais não seriam aplicáveis - como parre do pós-moderno, porque as normas assumem duas funçôes: obrigatótia e narrativa.

${ }^{27}$ Caso relatado in Jayme/Kohler, Europäisches Kollisionsrecht 1997- Vergemeinschaftung durch Säulenwechsel? IPRAX 1997, P. 385 ss.

${ }^{29}$ Convenção de Bruxelas: artigo $5^{\circ}, 1$ - Em matéria contratual, perante o tribunal do lugar onde a obrigação que serve de fundamento ao pedido foi ou deva ser cumprida; em matéria de contrato individual de trabalho, esse lugar é o lugar onde o trabalhador efetua habitualmente o seu trabalho e, se o trabathador não efetuar habitualmente o seu trabalho no mesmo país a entidade patronal pode igualmente ser demandada perante o tribunal do lugar onde se situa ou se situava o estabelecimento que contratou o trabalhador.

${ }^{29}$ Veja Erk Jayme, Osservazioni per una teoria postmoderna della comparazione giurdica, in Rivista di Diritto Civile, ano XIMI, 1997, nr. 6- parte prima, p.816ss. 
Após analisar estes dois exemplos da jurisprudência, passo agora a tratar de uma figura nova. O contrato pós-moderno por excelência, o contrato de time-sharing, que é a multimpropriedade. ${ }^{30}$

No momento, este modelo contratual tem recebido muita atenção da jurisprudência na Europa, tendo sido objeto de uma enormidade de casos e muitas decisões ou julgados que buscam solucionar o problema da lei aplicável e também - problema da competência jurisdicional aplicável a essa matéria. ${ }^{31}$

O time-sharing é um contrato que normalmente tem elementos de estraneidade porque, geralmente, são turistas de países do norte da Europa, os quais adquirem um imóvel situado num país no mar mediterrâneo, ou nas ithas canárias. Nesse contrato - cujo imóvel está comumente perto de uma praia ou sítio turístico - deve-se considerar os problemas de proteção do consumidor adquirente desse imóvel, em caso de conclusão desse contrato fora do local comercial da venda. ${ }^{32}$

Esse contrato consiste na transferência de um direito de uso (ou habitação) de um imóvel por um período determinado. Trata-se de um contrato complexo, que inclui normalmente alguns serviços, pois o adquirente paga uma soma para a manutenção do prédio, para a administração do imóvel, etc.

É uma associação de troca que pode proporcionar uma semana na Espanha ou em Portugal, por exemplo. É um contrato que apela também ao sentimento, porque o turista permite 'sentir-se' proprietário por uma semana de uma casa perto de uma praia. ${ }^{33}$

Esse contrato, o contrato de time-sharing, é pós-moderno, pois é misto e de difícil classificação, uma vez que não observa a distinção clássica entre móvel e imóvel.

$\mathrm{Na}$ Europa existem paises que dispõem de uma legislação especial em matéria de mulri-propriedade - sobretudo Portugal, que regulou de maneira exaustiva esses problemas que concernem à multi-propriedade -, dando-se conta da necessidade de proteção do adquirente na comunidade européia. ${ }^{34}$

Existe ainda uma diretiva da Comunidade Européia, de 26 de outubro de 1994, concernente à proteção do adquirente em alguns aspectos do contrato de aquisição de direito de utilização por tempo parcial de propriedade imobiliária. ${ }^{35}$

${ }^{30}$ Jayme, Recueil des Cours, pg. 247 e seg.

3 Veja Jayme/Kohler, Europäisches Kollisionsrecht - Der Dialog der Quellen, IPRAX 1995, p. 343.

32 Veja detalhes in Erik Jayme, "Europäische Kollisionstecht: Neue Aufgaben, neue Techniken", Europäische Binnenmarkt, IPR und Rechstangleichung, Hommelhoff/Jayme/Mangold (Ed.), C.F. Müllet, Heidelberg, 1995, p. 42-43.

33 Veja Erik Jayme, Neues Internationales Privatrecht für Time-Sharing-Vertäge- Zum TeilzeitWohnrechtegesetz voin 20.12.1996, IPRAX 1997, p. 233.

34 Jayme, ZfRV 1997, P. 235.

35 Diretiva 94/47/CE de 26 de outubro de 1994. 
Mister algumas palavras sobre a diretiva: afinal, o que é uma diretiva no direito europeu? Bem, a Diretiva é um ato legislativo da comunidade que vincula os Estados ao que concerne à finalidade da diretiva, obrigando os Estados-Membros a transpô-la nos sistemas nacionais. Os Estados, porém, ficam livres para determinar que medidas serão tomadas para atender essa ditetiva.

É uma legislação - podemos afirmar pós-moderna - porque há três textos que assumem simultâneamente importância para tesolver os casos: em primeiro, há a lei nacional, que transpõe a diretiva; em segundo, a diretiva em si e suas normas, porque o juiz é livre para interpretar a lei nacional à luz do direito europeu (logo, da Diretiva); em terceiro, existem os considerandos das diretivas (preâmbulos semelhantes aos dos Tratados Internacionais), os quais fixam sua finalidade e são importantes porque motivam a norma internacional.

Os considerandos são muitos importantes, porque no direito comunitário europeu, as diretivas sem motivação são nulas.

Então, são três textos a consultar para resolver um só caso.

A diretiva, a qual mencionei, sobre multi-propriedade, contém uma regra de direito internacional privado. ${ }^{36} \mathrm{O}$ arrigo 9 dessa diretiva afirma que os Estados-Membros devem tomar as medidas necessárias para - qualquer que seja a lei aplicável no caso de timeshating - que a pessoa que o adquire não fique desprovida da proreção da diretiva européia (mínimo standard de proteção eutopeu), quando o imóvel estiver situado no território de outro Estado-Membro.

No direito internacional privado pós-moderno, esta é uma regra unilateral, que protege o adquirente, considerado a parte mais vulnerável, porque é 'pressionada' pelo desejo de ter uma propriedade no estrangeiro dessa forma.

Por outro lado, a diretiva visa também uma finalidade completamente diferente: promover o bom funcionamento do mercado interno, evitando distorçóes de concortência nos mercados nacionais. Sob essa ótica, tem sentido limitar essa proteção sobre contratos concernentes a imóveis situados em certos territórios na Europa. ${ }^{37}$ O 'double coding' - principal característica da arquiretura pós-moderna - emerge claramente aqui em direito internacional privado.

Passo a um outro ponto da diretiva que é uma questão - também muito interessante - da proteção ao adquirente por meio da determinação da língua utilizada na redação de um contrato, que também está regulada pela Europa.

O contrato é documento que porta informações prescritas pela diretiva e - eu cito deve ser redigido um entre uma das Línguas oficiais da Comunidade Européia, numa língua de um dos Estados-Membros, para proteger o adquirente, que não deve ser privado do uso da língua que conhece.

${ }^{36}$ A Veja Jayme, Erik, Europäisches Schuldvertragsübereinkommen, vergleichendes Übersetzen, TimeSharing-Verträge, IPRAX 1995, pg. 135.

37 Jayme ZfRV 1997, p. 235. 
Com efeito, é a língua nacional que se impõe, para protegê-lo, bem como a língua do país onde reside ou que escolheu. Euma regra inovadora, protegendo a identidade cultural do consumidor. É uma inovação, podemos dizer, em diteito europeu comunitário.

Passo agora ao último ponto dessa conferência, que é o direito internacional privado das obras de arte. Logo ao início da conferência, mencionei a arte pós-moderna. É muito interessante verificar que o fenômeno pós-moderno é cultural. As obras de arte tornaram-se objetos com regra especial no direito internacional privado. ${ }^{38}$

Na concepção clássica do direito internacional privado, as obras de arte, como as pinturas, por exemplo, eram consideradas coisas móveis. Em geral, se aplicaria a lei do local da situação da coisa, para determinar, por exemplo, a questão da propriedade.

Na Europa, agota, temos uma diretiva relativa à restituição de bens culturais ilegalmente exportados, datada de 1993 , e que possui disposição especial de conflito de leis. ${ }^{39} \mathrm{O}$ regtamento da propriedade cultural e também de sua restituição é regulado pela legislação do Estado-Membro. ${ }^{40}$

Segundo essa disposição, aplicamos, então, a lei do país de origem da obra de arte. ${ }^{41} \mathrm{E}$ uma inovação, devido à proteção das obras de arte nacionais: o bem culrural assume grande importância para a identidade cultural das pessoas que formam a nação. Essa idéia é uma idéia pós-moderna.

É muito interessante observar que o Tratado de Roma de instituição da Comunidade Européia (Tratado de Roma) tem no artigo 36 uma regra sobre a proteção desses bens culturais (Exceção à livre circulação de bens na comunidade), reservando-a aos Estados nacionais. Ou seja, a legislação nacionalé a que importa. ${ }^{42}$

É uma idéia pós-moderna, porque essa disposição bem reflete o respeito à identidade cultural das pessoas e aos sentimentos das pessoas que formam uma nação. Naturalmente, existem muitos problemas para determinar a nacionalidade de uma obra de arte. Temos discutido bastante na Europa o problema da nacionalidade das obras de arte, e vocês podem imaginar como é difícil de determinar a nacionalidade delas ${ }^{43}$.

Em direito internacional privado, a regra clássica era a da situação da coisa, ou seja, a aplicação da lei de onde está localizado o bem (lex loci rei sitae). Daí ser muito importante esta exceção, a qual determina a aplicação da lei de origem do bem cultural, sendo uma inovação que reflere o espirito pós-moderno. ${ }^{44}$

${ }^{36}$ Erik Jayme, The Status of cultural Property in German Private International Law, in Erik Jayme (Ed.) German National Reports in Civil Law Matters for the XIVth Congress of Comparative Law in Athers 1994, Heidelberg, p. 8fi.

39 Richuinie 93/7/EWG äber die Rückgabe von unrechtmässig aus dem Hoheitsgebiet eines Mitgliedstaats verbrachten Kulturgütern, Abl EG L 74, p. 74.

${ }^{40}$ Vejâ Mussgnug, Das Kunstwerk im internationalen Recht, in Kunst und Recht, Heidelberg, 1985, p. 15ss.

41 Veja Erik Jayme, Anknüpfungsmaximen für den Kulturgüterschutz im Internatjonalen Privatrecht, in Études de Droit International en l'Honneur de Pierre Lalive, Helbing \& Lichtenhahn, Basiléia, 1993, p. 71̣ss.

42 Jayme, Études de Droit International en l'Honneur de Pierre Lalive, p. 720.

${ }_{43}$ Jayme, Etudes de Droit International en l'Honnesir de Pierre Lalive, p. 723.

${ }^{44}$ Jayme, Études de Droit International en l'Honneur de Pierre Lalive, p. 719. 
Senhoras e senhores, chego à conclusão.

Mencionei quatro elementos característicos da cultura pós-moderna: o pluralismo, a narrativa, a comunicação e o retorno dos sentimentos - um certo irracionalismo dos tempos pós-modernos. Observamos que esses fenômenos, que caracterizam o mundo pós-moderno, transformaram, em certa medida, o nosso direiro internacional privado.

O pluralismo reforçou a idéia de autonomia da vontade das partes. Por outro lado, protege-se identidade cultural da pessoa, de um nacional, por exemplo, e da nacionalidade das obras de arte. Essa idéia de pluralismo encontrou um lugar de honra no direito internacional privado pós-moderno. A comunicação, segundo os valores do pós-modernismo, conduz à idéia de integração. A jurisprudência alemã e inglesa citadas bem demonstram este desejo de atingir soluções uniformes na Europa. A técnica nova do diálogo entre fontes legslativas: existem as convençōes internacionais, a lei nacional e as diretivas - as quais, por sua vez, dispõem de três textos. Esse diálogo das fontes é um fenômeno novo e impactante, porque antes se considerava apenas a idéia de hierarquia entre as fontes, e não a de uma aplicação simultânea, de um diálogo entre elas.

Também as convençōes internacionais assumem dupla função: regulam conflitos, que podemos chamar de inter-regionais, porque na Europa agora pensamos nesses termos; mas rambém servem como modelo para transformar os sistemas nacionais.

O terceiro valor, a narração, demonstra-se na emergência de notmas narrativas. Isto quer dizer que, nas regras de direito, o juiz deve considerar várias normas como, por exemplo, a questão dos três textos das diretivas, para resolver um só caso prático.

O quarto valor: o retorno dos sentimentos e a proteção da identidade cultural, têm uma certa influência no direito internacional privado, ral como se viu no caso brasileiro, no qual, segundo a Corte, deve-se aplicar a lei nacional à senhora brasileira domiciliada na Espanha para determinar a sua responsabilidade. É o renascimento do princípio da nacionalidade, en virtude da proteção da identidade cultural do indivíduo.

Gostaria, ao fim dessa conferência, de salientar que devemos muito aos autores da América Latina no que concerne à discussão sobre a relação entre a cultura pós-moderna e o direito. ${ }^{45} \mathrm{Na}$ Espanha, também se discute muito esses problemas: há alguns meses, uns jovens professores de Granada publicaram um artigo sobre o direito internacional privado e pós-modernismo. ${ }^{46}$

É um tema apaixonante e eu agradeço muito à Faculdade de Direito da Universiade Federal do Rio Grande do Sul de ter escollhido esse tema para a primeira conferência que faço no Brasil. Muito obrigado.

45 Veja, por todos, Ghersi, Carlos Alberto, La Posmodernidad Juridica, Buenos Aires, 1995.

46 SANCHEZ LORENZO, Postmodernismo y Derecho internacional priwado, Revista espanola de Derecho internacional XIV1 (1994), 557 ss 